\title{
Het openbaar accountantsberoep als professioneel beroep
}

Prof. Dr. A.J. Bindenga

\section{Inleiding}

Jarenlang hebben de beroepsorganisaties van accountants ervoor geijverd het accountantsberoep het aanzien in de maatschappij te geven dat past bij een professioneel beroep. In Nederland heeft ook de wetgever erkend wat de functie van de openbaar accountant inhoudt. De laatste jaren is er echter een tendens merkbaar dat de samenleving twijfelt aan de professionaliteit van het accountantsberoep. Het is daarom zinvol een beschouwing te geven over de inhoud van een professioneel beroep in het algemeen en het accountantsberoep in het bijzonder.

In paragraaf 2 van dit artikel ga ik in op de kenmerken van een professioneel beroep en op het professionaliseringsproces van beroepen, waarna ik in paragrauf 3 de professionalisering van het accountantsberoep aan de orde zal stellen. In paragrauf 4 behandel ik recente ontwikkelingen. Tot slot trek ik in paragrauf 5 enkele conclusies.

\section{Professioneel beroep en professionaliseringsproces}

Het omschrijven van de inhoud van het begrip beroep is niet eenvoudig. Op de vraag wanneer bepaalde activiteiten in de samenleving worden aangeduid als een beroep, hebben vele deskundigen getracht antwoord te geven. De primaire ontstaansgrond van een beroep dient te worden gezocht in de maatschappelijke arbeidsverdeling. Het onderscheid tussen een functie en een beroep is in de praktijk echter niet gemakkelijk. Zowel een functie als een beroep is een geheel van bij elkaar behorende activiteiten. Het begrip beroep is echter meer generaliserend. Daarom acht ik de volgende definiëring doelmatig:

Prof.Dr. A.J. Bindenga is hoogleraar Accountancy aan de Erasmus Universiteit Rotterdam en partner bij Ernst \& Young te Rotterdam.
'Een bcroep is een aantal bij elkaar behorende activiteiten die op een zekere ervaring en deskundigheid berusten en die als een volledige dagtaak in de maatschappij tegen een geldelijke beloning kunnen worden verricht'.

De volgende vraag is wanneer een beroep als een professioneel beroep kan worden gekarakteriseerd. Hierbij stuit men ook op het begrip 'vrij beroep'. Deze term wordt in Nederland nog steeds gebruikt, hoewel naar mijn oordeel de vlag de lading niet meer dekt. Indien men namelijk tracht te omschrijven wat onder vrij beroep moet worden verstaan, moet inhoud worden gegeven aan het begrip 'vrijheid'. 'Vrij' kan in verschillende betekenissen worden gebruikt. Indien het gaat om een vrij beroep zijn er ten minste twee begripsomschrijvingen van belang. Vrij kan in de eerste plaats betekenen een economisch-juridische zelfstandigheid, dus niet in dienstverband werkzaam zijn. In de tweede plaats kan men het oog hebben op vrijheid van handelen, naar eigen inzicht handelen, niet gehinderd door anderen. Vrijheid kan dus slaan op uiterlijke vrijheid of innerlijke vrijheid. Een uiterlijke vrijheid is soms een voorwaarde voor de innerlijke vrijheid, maar er zijn ook situaties waarbij uiterlijke dwang juist kan leiden tot een sterkere ervaring van innerlijke vrijheid.

Oorspronkelijk voldeed de beoefenaar van een vrij beroep aan beide soorten vrijheid. Net als vele andere beroepswerkzaamheden is de uitoefening van een vrij beroep een maatschappelijke taak die zelfstandig wordt uitgevoerd. Het vrije beroep onderscheidde zich van de overige beroepswerkzaamheden doordat de arbeid enerzijds intellectuele arbeid betreft en anderzijds doordat er een zekere mate van anticommercialiteit aan is verbonden. Bij het ontstaan van dit soort beroepen in de tijd van de Romeinen pleegde men wel te zeggen, dat de 'do ut des'-verhouding niet bestond. Letterlijk vertaald betekent dit 'ik geef, opdat gij geven zult' of anders gezegd 'geen prestatie zonder tegenprestatie'. Bij het vrije beroep was dit niet 
het geval. In het huidige tijdsbeeld kan dit eigenlijk worden gezien als het laten prevaleren van de prestatie boven het particulier opbrengstbelang. Samenvattend zou men kunnen stellen dat de hoofdkenmerken van het vrije beroep zijn:

- Het betreft het aanbieden van intellectuele arbeid aan de samenleving.

- De beroepsbeoefenaar verricht zijn activiteiten economisch en juridisch zelfstandig.

- Bij het uitoefenen van het beroep gaat het leveren van de prestatie boven het particulier opbrengstbelang van de beroepsbeoefenaar.

Bij nadere beschouwing van deze kenmerken van het begrip 'vrij beroep', blijken er grote overeenkomsten te zijn met het begrip 'professioneel beroep'. In het algemeen is een professioneel beroep een beroep dat is gebaseerd op het begrip van de theoretische structuur van een bepaald kennisgebied of van een bepaalde wetenschap en op de bekwaamheden die bij een dergelijk begrip behoren. Dit begrip en deze bekwaamheden hebben betrekking op vitale belangen van de mensheid. De activiteiten van de professionele beroepsbeoefenaren worden bepaald door kennis van algemeen karakter en door verworven wijsheid en ervaring. Hierbij beschouwen de beroepsbeoefenaren het als een gebod om onbaatzuchtig diensten te verlenen aan cliënten.

Ik heb in een vroegere publicatie ${ }^{1}$ uiteengezet dat er drie kenmerken zijn van een professioneel beroep, namelijk:

a 'bodv of knowledge'

Dit houdt in dat de beroepsbeoefenaar een systematisch geheel van theoretische kennis en praktische bekwaamheden dient te bezitten. $\mathrm{Er}$ is een relatief lange theoretische opleiding nodig en een flinke periode van praktische ervaring.

$b$ 'code of ethics'

Dit betekent dat voor de professionele beroepsbeoefenaren geschreven en ongeschreven gedragsregels voor fatsoen en omgang bestaan. Het bestaan van gedragsregels is enerzijds vereist ter bescherming van de gebruikers van de diensten, anderzijds van de beroepsbeoefenaren zelf.

Een beoefenaar van een beroep die diensten verleent zonder professioneel karakter, vindt veelal gebruikers tegenover zich die de inhoud van de diensten kunnen beoordelen. Bij de professionele diensten is de situatie anders. De gebruiker wordt niet geacht een oordeel te hebben over de wijze waarop de diensten worden verricht. Hij moet daarom worden beschermd door een ethische code van de beroepsbeoefe- naren. Onder die code vallen ook de normen die gesteld moeten worden met betrekking tot collegiale relaties. Deze zijn bedoeld om de standaard van het beroep te beschermen en de leden van het beroep te weerhouden van onjuiste praktijken. Ook de onbaatzuchtige verlening van diensten wordt onder de ethische code geacht begrepen te zijn. De beoefenaar van een professioneel beroep zou de dienstverlening primair moeten achten, de betaling ervan secundair.

$c$ 'serving of vital needs'

Hiermee wordt bedoeld dat het beroep van vitaal maatschappelijk belang is. Het beroep dient een vitale functie in de samenleving. Dit is het geval als het beroep systeemscheppend is. Een sociaal systeem is een samenhangend geheel van intermenselijke relaties en de daarbij behorende patronen van verwachtingen, normen en ideeën. Elk sociaal systeem tendeert naar zelfhandhaving en aanpassing in een proces van voortdurende confrontatie met zijn omgeving. In wezen is dit proces een proces van schepping en herschepping. Met hun systeemscheppende functies vervullen de intellectuele beroepsbeoefenaren vitale functies met betrekking tot de zelfhandhaving en aanpassing van het sociale systeem waarbinnen die beroepen worden uitgeoefend. Voorbeeld van systeemscheppende functies zijn cultuur- of waardescheppende functies zoals denken, onderzoeken en analyseren, alsmede structuur- of ordescheppende functies, zoals beheren, administreren en bemiddelen. Ook socialiserende functies zoals voorlichten en adviseren behoren ertoe.

Zoals blijkt uit het vorenstaande is zowel bij het geven van inhoud aan het begrip vrij beroep in traditionele zin als bij het professionele beroepsbegrip sprake van een zekere anticommercialiteit bij het uitvoeren van de werkzaamheden. In het vervolg van dit artikel zal blijken dat met name ten aanzien van dit kenmerk belangrijke ontwikkelingen hebben plaatsgevonden.

Indien men zich afvraagt hoe een beroep zich ontwikkelt tot een professioneel beroep stuit men op het begrip professionaliseringsproces. Een dergelijk proces kent verschillende stadia, die zich echter niet bij elk beroep in dezelfde volgorde voordoen. In de sociologische literatuur ${ }^{2}$ worden de volgende stadia vrijwel altijd genoemd:

- de oprichting van een belangenvereniging; Hierdoor worden bekwame en onbekwame beroepsbeoefenaren van elkaar gescheiden. De als bekwaam gekenschetste beroepsgenoten zoeken aansluiting bij elkaar om de belangen van het beroep als zodanig, maar ook hun 
eigen belangen zo goed mogelijk te behartigen.

- de naam van het beroep wordt veranderd ter onderstreping van de kwaliteit, maar ook om zich af te zetten tegen de niet bekwame beroepsbeoefenaren. De wel bekwaam geachte professionals proberen een soort monopoliepositie te verwerven. Daardoor krijgen zij ook een zekere machtspositie. Hieraan zijn voor de samenleving zekere nadelen verbonden. Wel dient te worden bedacht dat de maatschappij deze positie op den duur alleen toestaat als zij overtuigd is van de deskundigheid van de professionele beroepsbeoefenaren en ook van het feit dat de regels van fatsoen worden nageleefd.

- het instellen van gedragsregels;

Elke beroepsbeoefenaar zal zich hieraan dienen te houden om niet te worden uitgesloten.

Dikwijls leiden de gedragsregels tot een formele ethiek met bijbehorende tuchtrechtspraak.

- een wettelijke bescherming;

Door middel van het bedrijven van politieke activiteiten trachten de beroepsbeoefenaren hun beroep als gezaghebbend aanvaard te krijgen. Vooral een wettelijk beschermde titel en een algehele wettelijke regeling worden nagestreefd.

- het instellen van een wetenschappelijk verantwoorde opleiding en een eigen scholingsinstituut; de beroepsbeoefenaren kunnen zelf bepalen aan welke eisen de opleiding dient te voldoen.

In het algemeen kan worden gesteld, dat professionele beroepen die een professionaliseringsproces hebben doorlopen zoals in het voorgaande beschreven, behoren tot de 'oude' groep of de 'nieuwe' groep. De oude groep zijn die beroepen, die honderden jaren bestaan en die een zekere beschaving in de samenleving tot stand hebben gebracht. Hiertoe behoren onder meer beroepen op het gebied van rechtspraak, gezondheidszorg en religie. De nieuwe groep heeft dan betrekking op architecten, ingenieurs, sociaal werkers enzovoorts.

\section{De professionalisering van de openbaar accountant}

Ik zal in deze paragraaf eerst ingaan op de in het voorgaande genoemde stadia van het professionaliseringsproces. Onderzocht zal worden of het accountantsberoep deze stadia heeft doorgemaakt. Daarna zal ik nog releveren of het accountantsberoep voldoet aan de aan professionele beroepen toegedachte kenmerken.

In de eerste plaats de oprichting van een belangenorganisatie. Evenals in het Verenigd Koninkrijk ontstond in Nederland het beroep van accountant in de negentiende eeuw. In 1854 werd in
Schotland de eerste beroepsorganisatie gesticht om de erkenning als beroep te verwerven, maar ook om de kwaliteit van de beroepsuitoefening te bevorderen. Men stelde al snel hoge eisen aan het lidmaatschap. In Nederland ging het niet veel anders. In 1883 was het eerste kantoor van beroepsbeoefenaren gesticht onder de naam 'Bureeel van Boekhouding'. De oprichters van dit bureel gaven in 1894 de stoot voor de oprichting van de belangenvereniging Nederlandsch Instituut van Accountants. Tot de vereniging traden 71 leden toe zonder enige vorm van examen. Het bestuur stelde echter snel een zwaar examen in. Het instituut werd daardoor een elite-organisatie. Al snel ontstonden daarom andere belangenorganisaties, waarvan men lid kon worden zonder examen te doen of door een veel lichter examen af te leggen.

Doordat leden van het Niva aan hun naam gingen toevoegen 'lid Niva', onderscheidden zij zich van de in hun ogen onbekwame beroepsbeoefenaren. Het Niva heeft vele jaren geijverd om de beroepsethos te versterken. Vooral na afloop van de interne perikelen door de strijd met de Nederlandsche Accountants Vereeniging ${ }^{3}$ heeft het Niva jarenlang krachtig voor de belangen van het beroep gestreden. Men kan zelfs stellen dat de beroepsorganisatie het Nederlandse accountantsberoep niet alleen in Nederland een belangrijk aanzien heeft gegeven, maar ook in het buitenland. Vertegenwoordigers van de beroepsorganisatie hebben in internationale organen altijd een belangrijke rol gespeeld. Als enig klein land maakte Nederland bijvoorbeeld deel uit van de organisaties die het International Accounting Standards Committee hebben opgericht.

In de tweede plaats de naamsverandering. De oprichters van het eerste kantoor noemden zich boekhouders. Maar Van Dien noemde zich in 1893 voor het eerst accountant en de opgerichte belangenorganisatie was een instituut van accountants. Doordat iedereen zich echter accountant mocht noemen werd de toevoeging lid Niva bedacht en enkele tientallen jaren later ook lid Vaga. Lange tijd waren deze twee toevoegingen volgens de beroepsbeoefenaren zelf, maar ook in de ogen van het publiek het kenmerk van kwaliteit. $\mathrm{Bij}$ het streven naar een wettelijke regeling werd de term registeraccountant bedacht. De registeraccountant kreeg een monopoliepositie, doordat hij wettelijk de unieke bevoegdheid kreeg om verklaringen van getrouwheid af te geven. Ook in andere landen geschiedde hetzelfde door toevoeging van 'chartered', 'certified' of een andere aanduiding.

Vervolgens het derde stadium; het instellen van gedragsregels. Zonder overdrijving kan worden gesteld dat de huidige Gedrags- en Beroepsregels in Nederland zware normen zijn. Hoewel in andere 
landen de beroepsreglementering over het algemeen lichter is, kent men vrijwel overal een 'code of ethics'. Ook de International Federation of Accountants streeft via haar Ethical Committee naar een kwalitatief hoge beroepsreglementering.

In Nederland zijn de beroepsregels in eerste instantie opgesteld door Th. Limperg, de grondlegger van de accountancy in Nederland. In 1907 werden zij aangenomen door de leden van de Nederlandsche Accountants Vereniging die door een scheuring binnen het Nederlandsch Instituut van Accountants was ontstaan. In 1947 heeft een commissie onder leiding van dezelfde Limperg de regels herzien en op een nog hoger peil gebracht. In 1962 werden zij ongewijzigd overgenomen bij het totstandkomen van de wetgeving, maar in 1973 werden zij enigszins gemoderniseerd. Thans wordt overwogen de GBR weer aan te passen door in belangrijke mate uit te gaan van de door de IFAC op te stellen regels.

Over het vierde stadium kan ik kort zijn, hoewel het zeer lang heeft geduurd voor de wettelijke bescherming in Nederland tot stand is gekomen.

Reeds bij de oprichting van het Niva was één van de doelstellingen te komen tot een wettelijke regeling van het accountantsberoep. Na vele pogingen is dit uiteindelijk in 1962 gelukt. De registeraccountant is wettelijk geregeld en in 1974 ook de zogenaamde accountant-administratieconsulent. Sinds 1993 zijn de bevoegdheden van beide groepen accountants gelijk. In 2000 is de Nederlandse overheid gestart met een evaluatie van de accountantswetgeving, maar het is niet te verwachten dat de wet wordt afgeschaft.

Ten slotte het vijfde stadium. Ruim honderd jaar geleden werd door het beroep in Nederland een eigen opleiding gestart. In vergelijking met andere landen stond deze opleiding op een zeer hoog niveau. De beroepsorganisatie heeft deze opleiding altijd in eigen hand gehouden tot enkele jaren geleden de NIVRA-Nijenrode-opleiding ontstond. Hierdoor wordt het onderwijs weliswaar niet langer door de beroepsorganisatie zelf georganiseerd, maar de eindtermen van de opleiding worden nog wel door het beroep zelf aangegeven. Door de wettelijk ingestelde accreditering van universitaire opleidingen en het regelmatig optreden van visitatiecommissies wordt ook centraal het niveau bewaakt. In andere landen ligt deze situatie soms anders. In de Angelsaksische landen bestaan slechts examens bewaakt door de beroepsorganisatie en wordt de opleiding aan anderen overgelaten. Dit is ook het geval in sommige Europese continentale landen.

Ik acht het verdedigbaar om te stellen dat het openbaar accountantsberoep de professionaliseringsstadia heeft doorlopen. Wel moet ik aantonen dat het beroep de professionele kenmerken heeft. Door de zware opleiding is het duidelijk dat voor het uitoefenen van het accountantsberoep men een systematisch geheel van theoretische kennis en praktische bekwaamheden dient te bezitten. In vrijwel alle landen ter wereld, tegenwoordig ook in Nederland, is het wettelijk verplicht een aantal jaren in de praktijk werkzaam te zijn alvorens men het beroep mag uitoefenen. De 'code of ethics' is ook aanwezig, maar moeilijker is het te verklaren waarom het accountantsberoep een vitaal maatschappelijk belang dient. In dit verband zou men zich moeten afvragen of betrouwbare informatievoorziening noodzakelijk is voor de samenleving. Ik meen dat de samenleving op de lange termijn schade zou worden berokkend indien de informatievoorziening niet betrouwbaar zou zijn. Het is nog steeds zo dat de verschaffers van kapitaal behoefte hebben aan een onafhankelijk oordeel over de betrouwbaarheid van door ondernemingen en andere organisaties verstrekte informatie. Deze publieke functie, die alleen kan bestaan als de openbaar accountant deskundig en onafhankelijk is, is van vitaal belang in het allocatieproces van financiële middelen.

\section{Recente ontwikkelingen rond de professionaliteit van de openbaar accountant}

Professionele beroepen zijn onderhevig aan een aantal tendensen. Ook het openbaar accountantsberoep ontkomt hier niet aan. Vele van deze tendensen hebben te maken met veranderende visies uit de samenleving. Toch meen ik dat deze veranderingen veelal door de beroepsbeoefenaren zelf zijn veroorzaakt. Hun activiteiten hebben vaak reacties teweeggebracht waar de beroepsbeoefenaren zelf geen greep meer op hebben.

Als een algemene tendens noem ik de 'ontsokkeling' van het professionele beroep. Met deze term, voor het eerst gebruikt door Anne van der Meyden, wordt bedoeld dat de samenleving niet meer opkijkt tegen professionele beroepen. Men heeft niet zo veel ontzag meer voor de arts en de advocaat. Ook zij worden gezien als mensen die hun brood moeten verdienen door te werken. Men is van mening dat men gerust met hen kan onderhandelen over de prijs die voor hun diensten moet worden betaald. Dit geldt zeker voor de accountant. Hij wordt niet meer gezien als de grote financiële deskundige aan wie elk administratief en financieel probleem kan worden voorgelegd. Ook hij is van zijn 'sokkel' afgedaald naar de gewone man.

Met betrekking tot het openbaar accountantsberoep zijn er echter ook een groot aantal specifieke tendensen. Zonder te streven naar volledigheid noem ik met name enkele ontwikkelingen die 
invloed hebben op de professionaliteit van de openbaar accountant.

In de eerste plaats kan worden gewezen op de bureaucratisering van de organisaties waarin de openbaar accountant zijn beroep uitoefent.

Een bureaucratie is een bestuursvorm van grote organisaties waarvan de inrichting is gebaseerd op rationaliteit. Er is een hiërarchische ordening van functionarissen, een centrale leiding, en beslissingsprocedures vinden plaats volgens algemene regels. Professionele beroepen, waaronder het accountantsberoep, werden aanvankelijk solitair uitgeoefend. De eerste samenwerkingsverbanden van accountants waren nog niet te kenschetsen als bureaucratische organisaties, omdat de functies nog werden verdeeld zonder te letten op de aard van de dienstverlening en het niveau van de dienstverleners.

Hoewel er nog vele accountantsorganisaties bestaan waarin dit laatste nog steeds het geval is, zijn in de mammoetkantoren toch in belangrijke mate bureaucratische kenmerken aanwezig. Bestuurders van deze organisaties vormen het strategisch beleid en ook het vaktechnisch beleid. Voor de audit-praktijk worden controlemethodologieën samengesteld waaraan de beroepsbeoefenaren zich dienen te houden. De professional moet werken in organisaties waar geüniformeerde arbeidsvoorwaarden bestaan. De vraag die moet worden beantwoord is of dit soort zaken het karakter van het professionele beroep raakt. Hoewel zekere vrijheden worden ingeperkt, heeft een openbaar accountant in een grote organisatie naar mijn mening nog steeds voldoende innerlijke vrijheid. Soms zegt men wel dat de professionele oordeelsvorming voor de uitoefening van het beroep nodig blijft. Maar er zijn meer factoren zoals de onderlinge vertrouwensrelaties en de eigen verantwoordelijkheid van de professionele beroepsbeoefenaren. De openbaar accountant is nog steeds persoonlijk verantwoordelijk voor de uitoefening van zijn beroepsactiviteiten. Het tuchtrecht van de beroepsorganisatie is een persoonlijk tuchtrecht. De bureaucratisering als zodanig tast de professionaliteit derhalve maar zeer ten dele aan.

De tweede tendens is de specialisatie. Dit houdt in dat het totale vakgebied niet meer door één beroepsbeoefenaar kan worden overzien. De professional was van nature generalistisch ingesteld, maar binnen het vakgebied ontstaan specialisaties. Het gevolg hiervan is dat de homogeniteit van de beroepsgroep verdwijnt. De voorwaarden en omstandigheden binnen de beroepsuitoefening kunnen daardoor gaan verschillen. Binnen het accountantsberoep zijn vele specialismen ontstaan, zoals de belastingadviespraktijk, de administratief-organisatorische adviesverlening, de EDP- auditing, de milieurapportage, et cetera. Hoewel de generalistisch ingestelde accountant op al deze deelterreinen slechts een globale deskundigheid bezit, kan in het algemeen niet worden gesteld dat specialisatie de professionaliteit van het openbaar accountantsberoep aantast. Het vitale belang van de betrouwbaarheid van informatie blijft aanwezig, ook al worden op deelterreinen werkzaamheden door specialisten uitgevoerd.

Als derde tendens noem ik de institutionalisering van het beroep. In tegenstelling tot de bureaucratisering en specialisatie gaat hiervan wel invloed uit op het professionele karakter van het beroep van openbaar accountant. Over het institutionaliseringsproces in het algemeen is veel geschreven. Ook over de institutionalisering van het accountantsberoep bestaat de nodige literatuur. ${ }^{4}$

Institutionalisering is een proces waardoor zich instellingen van de samenleving ontwikkelen. Deze instellingen noemt men instituties. Zij hebben meestal betrekking op essentiële functies van de samenleving. Het proces wordt wel omschre$v^{v} n^{5}$ als het fundamenteel antropologisch proces, waarin individuele menselijke handelingen worden geobjectiveerd tot vaste min of meer normatieve handelingspatronen, die als collectieve vormen kunnen blijven bestaan onafhankelijk van handelende individuen. Als zodanig dwingen de instituties de individuele mens om bepaalde handelingen op bepaalde wijze te verrichten. Maar zij verschaffen hem ook de voor zijn handelen onmisbare sociale stabiliteit en zekerheid.

De openbaar accountant is al geruime tijd onderhevig aan een proces van institutionalisering. Accountants als deskundigen met betrekking tot financiële verantwoordingen hebben zich opgeworpen als controleurs van dit soort informatie. Accountants werden auditors. Deze activiteit is door de samenleving geaccepteerd en uiteindelijk wettelijk verankerd. Accountantscontrole is daardoor een institutie geworden. Vele beroepsorganisaties van accountants hebben hiervoor ook het nodige werk gedaan. Wettelijke bescherming en wettelijke regeling waren in het professionaliseringsproces belangrijke doeleinden.

Door het totstandkomen van een wettelijke regeling zet zich echter ook een proces van deprofessionalisering in, doordat de institutionalisering grote gevolgen heeft. Accountantscontrole is een institutie van de samenleving geworden en de samenleving wenst deze zelf te behartigen en niet over te laten aan de beroepsbeoefenaren. Vooral de laatste tijd hoort men verkondigen dat zelfregulering door het beroep niet de juiste weg is. Dit heeft zelfs betrekking op een van de twee pijlers van het openbaar beroep. de onafhankelijkheid. Lang heeft het beroep hiervoor zelf regels 
gesteld, maar thans zijn het de overheid en andere toezichthoudende organen die in het geweer komen. Opvallend hierbij is dat deze de formele onafhankelijkheid blijkbaar veel belangrijker vinden dan de onafhankelijkheid in geesteshouding. Ook de andere pijler, de deskundigheid, wordt door derden bediscussieerd. Buitenstaanders, cliënten en de overheid kunnen de inhoud van de dienstverlening beoordelen en wensen er met de beroepsbeoefenaren over te overleggen. Ook de monopoliepositie van het beroep is al lang niet meer aanwezig; ook andere beroepsbeoefenaren geven oordelen over informatie. Dit wordt nog eens in de hand gewerkt door het feit dat ook andere dan financiële informatie van belang is voor het allocatieproces van productiemiddelen. Kortom: de wettelijke regeling gaf erkenning en bracht bescherming, maar betekende het einde van het professionaliseringsproces. De institutie is te officieel geworden om aan het beroep over te laten.

De laatste tendens die ik aan de orde wil stellen is de commercialisering. Wellicht is deze mede het gevolg van de institutionalisering. Als zodanig houdt commercialisering in dat de kenmerken die worden toegeschreven aan het vrije bedrijfsleven zich ook gaan afspelen binnen het professionele beroep. Een wezenskenmerk van het professionele beroep was anticommercialiteit. Het ging om de prestatie boven het particulier opbrengstbelang. Dit proces van commercialisering houdt in dat de beroepsbeoefenaren trachten de opbrengst van hun prestatie gelijkwaardig te doen zijn aan het maatschappelijk nut. Men is slechts bereid een prestatie te leveren als men een gelijkwaardige tegenprestatie ontvangt. Daardoor groeien professionele beroepsbeoefenaren en naar winst strevende ondernemingen naar elkaar toe, vooral als deze beroepsbeoefenaren werkzaam zijn in een bureaucratische organisatie.

Het openbaar accountantsberoep is in belangrijke mate gecommercialiseerd. Men verkrijgt slechts opdrachten na concurrerende prijsopgaven. Voor het behouden van opdrachten is men bereid een stuk van de winstmarge op te offeren. De 'sales-specialists' zijn belangrijke personen geworden in de organisatie. Zij weten weinig van de grondslagen van het accountantsberoep en de accountantscontrole af, maar zij zijn wel de uitvoerders van het verkoopbeleid. Reclame en marketing zijn begrippen die niet meer weg te denken zijn in een grote accountantsorganisatie, evenals public relations en relatiemanagement. Op zich zouden al dit soort zaken de professionaliteit geen schade behoeven toe te brengen als men maar voor ogen zou houden dat de openbaar accountant de publieke functie blijft dienen. Het moet primair om het uitoefenen van de publieke functie blijven gaan. Dit is namelijk de functie waaraan het openbaar accountantsberoep het vitale maatschappelijke belang ontleent.

\section{Conclusies}

Aan het einde gekomen van deze beschouwing trek ik graag enkele conclusies die wellicht van belang zijn voor de toekomst van het openbaar accountantsberoep.

Het openbaar accountantsberoep heeft een proces van professionalisering doorgemaakt en een van de belangrijkste diensten van het beroep. de accountantscontrole, is een institutie van de samenleving geworden. Het beroep heeft alle kenmerken van een professioneel beroep en bij de uitvoering van de dienstverlening bestond lange tijd ook een zekere mate van anticommercialiteit. Door institutionalisering en commercialisering is dit laatste echter verdwenen. Ik meen dat dit ook voor andere professionele beroepen geldt. Zo zou men kunnen stellen dat in het algemeen de tijd van de professionele beroepen oude stijl voorbij is. De professionele beroepen nieuwe stijl dienen nog steeds wel vitale maatschappelijke belangen, maar leveren weinig prestaties meer zonder een gelijkwaardige tegenprestatie te ontvangen. Het is van groot belang dat het openbaar accountantsberoep niet alleen denkt aan een bevredigende commerciële beroepsuitoefening, maar zich vooral de maatschappelijke betekenis van de accountantsfunctie realiseert, namelijk de publieke functie. Indien dit in onvoldoende mate zou geschieden, zullen buitenstanders ingrijpen. Deze publieke functie is immers een institutie van de maatschappij.

\section{NOTEN}

1 A.J. Bindenga, 'Het vrije beroep van accountant', Samsom, 1973. Zie ook: A.J. Bindenga, Syllabus 'Grondslagen van het Accountantsberoep', Erasmus Universiteit Rotterdam, 2000.

2 Een van de oudste standaardwerken is: A.M Carr-Saunders en P.A. Wilson, 'The professions', Clarendon Press, 1933.

3 Ik wil hierbij graag verwijzen naar de geschiedschrijving van het Nederlandse accountantsberoep onder meer in: J. de Vries, 'Geschiedenis der Accountancy in Nederland', Van Gorcum, 1985

4 P.E. de Hen, J.G. Berendsen, J.W.

Schoonderbeek, 'Hoofdstukken uit de geschiedenis van het Nederlandse accountantsberoep na 1935', Van Gorcum, 1995, p. 268.

5 Onder anderen door de bekende socioloog A.C. Zijderveld. 